\title{
The efficacy of retreatment rotary and reciprocating files in the removal of filling material from root canals: A systematic review
}

\author{
Kaveh Nasiri ${ }^{*}$ and Karl-Thomas Wrbas ${ }^{1,2}$ \\ ${ }^{1}$ Department of Endodontics, Center for Operative Dentistry and Periodontology, University of Dental Medicine and Oral Health, Danube Private University \\ (DPU), Krems, Austria \\ ${ }^{2}$ Department of Operative Dentistry and Periodontology, Center for Dental Medicine, Oral and Maxillofacial Surgery, Medical Center, University of Freiburg, \\ Freiburg i.Br., Germany
}

\begin{abstract}
Background \& aim: One of the major goals of secondary root canal therapy is to promote maximal removal of filling material from root canals. This review study intended to investigate the efficacy of retreatment instruments with continuous motion versus reciprocating instruments that use adaptive motion during retreatment in the removal of filling material.

Methodology: An electronic search was conducted in these databases: PubMed, Cochrane Library, LILACS, and SIGLE. The articles were selected among those published between 2000 and 2019. The following keywords were used: Retreatment systems (D-RaCe, Mtwo retreatment, ProTaper retreatment, R-Endo) and Reciprocating systems (Reciproc, Reciproc Blue, Wave One, Wave One Gold). In addition, exclusion and inclusion criteria were used for the selection of the articles.

Results: Six articles were included in this review study. Four studies concluded that there was no significant difference between retreatment and reciprocating systems; one article reported that Reciproc system was more effective than ProTaper retreatment and Reciproc Blue systems; and the last one showed that Mtwo retreatment system was the least effective in comparison to reciprocating and retreatment systems in the removal of filling material from root canals.

Conclusion: This systematic review revealed that none of the systems could completely remove the filling material from the root canals. Thus, all systems are suitable and effective for retreatment. Furthermore, more clinical and laboratory trials are required to evaluate the efficacy of retreatment and reciprocating systems in reducing root filling material left in root canals during retreatment.
\end{abstract}

\section{Introduction}

One of the primary goals of the secondary root canal therapy is the removal of previous filling material from the root canals in order to gain access to the apical constriction for cleaning and shaping, resulting in the eradication of microorganisms from the root canals, which, in turn, increases the success rate of secondary root canal therapy $[1,2]$. Nevertheless, the removal of filling material such as gutta-percha (GP) and sealers is not easy [1]. Insufficient cleaning and inadequate root filling are the two main factors leading to root canal failure. Moreover, teeth with untreated canals and complication of instrumentation such as ledges, perforation or fractured instruments may require retreatment before final coronal restoration $[3,4]$.

In order to remove filling material from root canals, several instrumentation retreatment systems including D-RaCe, Mtwo retreatment, ProTaper retreatment, and R-Endo have been designed and manufactured for secondary root canal treatment. These files, which rotate in continuous motion, are particularly considered for the removal of root filling material [5-7]. There is yet another innovative system, Endo ReStart, which has been developed for the removal of filling material for retreatment procedures [8].

Despite being originally developed for the purpose of root canal instrumentation, systems with reciprocating motion, such as Reciproc,
Reciproc Blue, Wave One, and Wave One Gold are also suggested for secondary root canal therapy since they are flexible and have high resistance to cyclic fatigue $[2,5,9]$. The detailed description of all systems is shown in Table 1. The objective of the present review study was to assess retreatment and reciprocating systems used in continuous and adaptive motions, respectively, in the removal of filling material from root canals.

\section{Hypotheses}

\section{Null hypothesis}

The null hypothesis tested was that there is no significant difference between retreatment files with continuous motion and reciprocating files with adaptive motion in the secondary therapy during the removal of filling material from root canals.

${ }^{*}$ Correspondence to: Kaveh Nasiri, Department of Endodontics, Center for Operative Dentistry and Periodontology, University of Dental Medicine and Oral Health, Danube Private University (DPU), Krems, Austria, E-mail: DDS.Nasiri@web.de

Key words: reciprocating files, removal of filling material, retreatment files

Received: January 02, 2020; Accepted: January 13, 2020; Published: January 16, 2020 
Table 1. Detailed description of retreatment and reciprocating systems

\begin{tabular}{|c|c|c|c|c|}
\hline System & Manufacturer & File (Size/Taper) & Cross-section & File tip \\
\hline $\mathrm{D}-\mathrm{RaCe}$ & $\begin{array}{l}\text { FKG Dentaire SA, La } \\
\text { Chaux-de-Fond, Switzerland }\end{array}$ & $\begin{array}{l}\text { DR1: }(30 / 0.10) \\
\text { DR2: }(25 / 0.04)\end{array}$ & Triangular & $\begin{array}{l}\text { DR1: Active } \\
\text { DR2: Inactive }\end{array}$ \\
\hline Mtwo retreatment & VDW, Munich, Germany & $\begin{array}{l}\text { R15: }(15 / 0.05) \\
\text { R25: }(25 / 0.05)\end{array}$ & S-Form & $\begin{array}{l}\text { R15: Active } \\
\text { R25: Active }\end{array}$ \\
\hline ProTaper retreatment & $\begin{array}{l}\text { Dentsply Maillefer, } \\
\text { Ballaigues, Switzerland }\end{array}$ & $\begin{array}{l}\text { D1: }(30 / 0.09) \\
\text { D2: }(25 / 0.08) \\
\text { D3: }(20 / 0.07)\end{array}$ & Convex triangular & $\begin{array}{l}\text { D1: Active } \\
\text { D2: Inactive } \\
\text { D3: Inactive }\end{array}$ \\
\hline R-Endo & $\begin{array}{l}\text { Micro-Mega, Besancon, } \\
\text { France }\end{array}$ & $\begin{array}{l}\text { Rm: }(25 / 0.04) \\
\text { Re: }(25 / 0.12) \\
\text { R1: }(25 / 0.08) \\
\text { R2: }(25 / 0.06) \\
\text { R3: }(25 / 0.04)\end{array}$ & Triangular & $\begin{array}{l}\text { Rm: Inactive } \\
\text { Re: Inactive } \\
\text { R1: Inactive } \\
\text { R2: Inactive } \\
\text { R3: Inactive }\end{array}$ \\
\hline Endo ReStart & $\begin{array}{l}\text { Komet Dental, Lemgo, } \\
\text { Germany }\end{array}$ & $\begin{array}{l}\text { RE10: }(30 / 0.10) \\
\text { RE05: }(25 / 0.05)\end{array}$ & Double-S-Form & $\begin{array}{l}\text { RE10: Inactive } \\
\text { RE05: Inactive }\end{array}$ \\
\hline Reciproc & VDW, Munich, Germany & $\begin{array}{l}\text { R25: }(25 / 0.08) \\
\text { R40: }(40 / 0.06) \\
\text { R50: }(50 / 0.05)\end{array}$ & S-Form & $\begin{array}{l}\text { R25: Inactive } \\
\text { R40: Inactive } \\
\text { R50: Inactive }\end{array}$ \\
\hline Reciproc Blue & VDW, Munich, Germany & $\begin{array}{l}\text { R25: }(25 / 0.08) \\
\text { R40: }(40 / 0.06) \\
\text { R50: }(50 / 0.05)\end{array}$ & S-Form & $\begin{array}{l}\text { R25: Inactive } \\
\text { R40: Inactive } \\
\text { R50: Inactive }\end{array}$ \\
\hline Wave One & $\begin{array}{l}\text { Dentsply Maillefer, } \\
\text { Ballaigues, Switzerland }\end{array}$ & $\begin{array}{l}\text { Small: }(21 / 0.06) \\
\text { Primary: }(25 / 0.08) \\
\text { Large: }(40 / 0.08)\end{array}$ & $\begin{array}{l}\text { Modified convex triangular } \\
\text { (apical) Convex triangular } \\
\text { (coronal) }\end{array}$ & $\begin{array}{l}\text { Small: Inactive } \\
\text { Primary: Inactive } \\
\text { Large: Inactive }\end{array}$ \\
\hline Wave One Gold & $\begin{array}{l}\text { Dentsply Maillefer, } \\
\text { Ballaigues, Switzerland }\end{array}$ & $\begin{array}{l}\text { Small: }(20 / 0.07) \\
\text { Primary: }(25 / 0.07) \\
\text { Medium: }(35 / 0.06) \\
\text { Large: }(45 / 0.05)\end{array}$ & Parallelogram & $\begin{array}{l}\text { Small: Semi-active } \\
\text { Primary: Semi-active } \\
\text { Medium: Semi-active } \\
\text { Large: Semi-active }\end{array}$ \\
\hline
\end{tabular}

\section{Alternative hypothesis}

The alternative hypothesis in this systematic review was that there is a significant difference between retreatment and reciprocating files with continuous and adaptive motion respectively.

\section{Materials and methods}

In the present review study, a systematic search of journal papers was conducted in the four main databases, namely, PubMed, Cochrane Library, LILACS, and SIGLE. In doing so, the following search terms were used: "Retreatment", "D-RaCe", "Mtwo retreatment", "ProTaper retreatment", "R-Endo", "Reciproc", "Reciproc Blue", "Wave One", and "Wave One Gold". At the next stage, inclusion and exclusion criteria were employed to narrow down the articles accordingly.

The PICO process was used to develop literature search strategies for this systematic review. PICO items are defined as follows: P stands for population which refers to the teeth with poor obturation quality; I is intervention, referring to the retreatment systems; C stands for comparison, representing the reciprocating systems; and finally, $\mathrm{O}$ is the outcome and refers to the removal of root filling material. Both authors evaluated the articles separately to determine whether the studies met the inclusion and exclusion criteria or not.

\section{Inclusion criteria}

The eligibility criteria for the selection of the articles were: 1 . Articles must be published after the year 2000. 2. The studies must be original and conducted in vitro or vivo environment. 3 . The journal metrics including Impact Factor or CiteScore must be greater than 1 and 0.75 respectively. 4 . The subgroup of each group must not be less than 10 samples. 5. The samples must be standardized such as root canal curvature and fully formed root apex. 6 . The studies must be necessarily on the comparison between retreatment and reciprocating systems; the presence or absence of other systems is not of importance. 7 . The studies must be carried out employing at least one retreatment system with continuous motion and one reciprocating system with adaptive motion. 8. The articles must be written in English.

\section{Exclusion criteria}

The exclusion criteria for the selection of the articles were: 1 . Articles with the publication date prior to 2000 were excluded. 2 . Articles in which artificial teeth were used as the samples were excluded. 3. Case reports, studies conducted on animals, and review studies were excluded.

\section{Results}

The initial database search identified 750 articles out of which 171 were duplicates and therefore, were removed. Also, all articles that were not written in English and were published before 2000 were excluded, leaving 531 articles. The remaining articles were screened according to their title and the purpose of the study, resulting in the exclusion of a further 458 articles. The title and abstract of the remaining 73 articles were reviewed and evaluated individually by two investigators; as a result, a further 64 articles were removed and only nine articles were left, which were then assessed for eligibility, a full-text analysis leading to the deletion of three more articles. Consequently, at the end of the screening process, six articles were included in the qualitative synthesis of the present review study. Figure 1 illustrates a PRISMA flow diagram and the results of the search strategy. Table $2[5,10-14]$ shows the results and details of the selected articles.

\section{Discussion}

In the case of infection after initial root canal therapy, the most effective procedure to restore the teeth is secondary root canal therapy [15], which can be successfully performed through different $\mathrm{Ni}-\mathrm{Ti}$ systems in order to remove filling material from root canals $[14,16]$. This systematic review study investigated the effectiveness of retreatment 


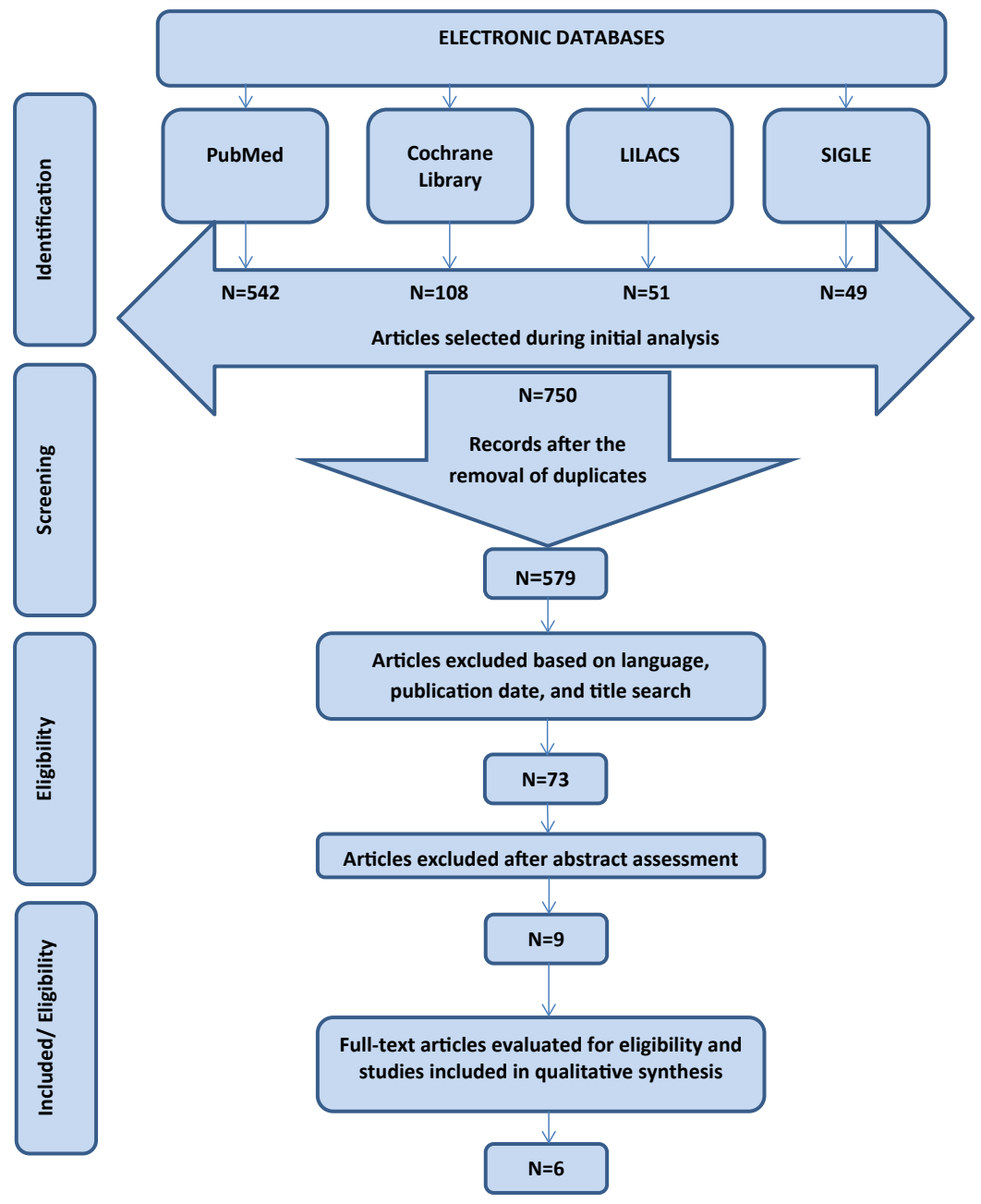

Figure 1. Flow chart of articles screening in the review study

Table 2. General information about included articles

\begin{tabular}{|c|c|c|c|c|c|}
\hline Authors & Year of publication & Study type & $\begin{array}{c}\text { Number of samples and } \\
\text { subgroups }\end{array}$ & Instruments/ motions & Results/ conclusions \\
\hline Madarati et al [5] & 2018 & In vitro study & $90 / n=18$ & $\begin{array}{l}\text { 1. } \mathrm{REC} * / \mathrm{AM} \dagger \\
\text { 2. } \mathrm{WO}^{*} / \mathrm{AM} \\
\text { 3. } \mathrm{S} 1 / \mathrm{AM} \\
\text { 4. } \mathrm{PTU}-\mathrm{R}^{*} / \mathrm{CM} \dagger \\
\text { 5. Mtwo-R*/ CM }\end{array}$ & $\begin{array}{l}\text { REC, WO, S1, and PTU-R were more effective than Mtwo-R in } \\
\text { removing root filling material }(\mathrm{P}<0.05) / \text { Reciprocating systems were as } \\
\text { effective as retreatment systems (excluding Mtwo-R). }\end{array}$ \\
\hline Rios et al [10] & 2014 & In vitro study & $60 / n=20$ & $\begin{array}{l}\text { 1. REC/AM } \\
\text { 2. WO/AM } \\
\text { 3. PTU-R/ CM }\end{array}$ & $\begin{array}{l}\text { No significant difference was observed among systems/ REC and WO } \\
\text { were as effective as PTU-R system. }\end{array}$ \\
\hline Silva et al [11] & 2015 & In vitro study & $40 / n=20$ & $\begin{array}{l}\text { 1. } \mathrm{WO} / \mathrm{AM} \\
\text { 2. PTU-R/ CM }\end{array}$ & $\begin{array}{l}\text { No significant difference was observed between systems/ All systems } \\
\text { were safe in removing filling material. }\end{array}$ \\
\hline Kasikci et al [12] & 2017 & In vitro study & $96 / n=24$ & $\begin{array}{l}\text { 1. H-files } \\
\text { 2. R-Endo/CM } \\
\text { 3. REC/AM } \\
\text { 4. PTU-R/CM }\end{array}$ & $\begin{array}{l}\text { No significant difference was observed among systems/ All systems } \\
\text { were effective in removing filling material }\end{array}$ \\
\hline Bago et al [13] & 2019 & In vitro study & $45 / n=15$ & $\begin{array}{l}\text { 1. REC-B*/AM } \\
\text { 2. REC/AM } \\
\text { 3. PTU-R/ CM }\end{array}$ & $\begin{array}{l}\text { REC removed significantly more filling material than REC-B and } \\
\text { PTU-R/ REC was found to be the most effective system. }\end{array}$ \\
\hline Delai el al [14] & 2019 & In vitro study & $30 / n=10$ & $\begin{array}{l}\text { 1. } \mathrm{WOG}^{*} / \mathrm{AM} \\
\text { 2. } \mathrm{PTU}-\mathrm{R} / \mathrm{CM} \\
\text { 3. } \mathrm{D}-\mathrm{RaCe} / \mathrm{CM}\end{array}$ & $\begin{array}{l}\text { No significant difference was observed among systems/ All systems } \\
\text { were safe in removing filling material. }\end{array}$ \\
\hline
\end{tabular}

$\mathrm{AM} \dagger$ : Adaptive motion; $\mathrm{CM}+$ : Continuous motion; REC*: Reciproc; WO*: Wave One; PTU-R*: ProTaper retreatment; Mtwo-R*: Mtwo retreatment; REC-B*: Reciproc Blue; WOG*: Wave One Gold 
instruments with continuous motion in comparison to reciprocating instruments that use adaptive motion during the removal of filling material from root canals.

According to the results of the present review study, four studies $[10-12,14]$ showed no significant difference between retreatment and reciprocating systems. Thus, the null hypothesis was confirmed whereas the alternative hypothesis was rejected. Furthermore, one in vitro study [13] reported that the Reciproc system is more effective in removing filling material from root canals. Hence, the null and alternative hypotheses were rejected and accepted, respectively. The last selected article, which was an in vitro study [5], reported that Mtwo retreatment system is less effective than reciprocating and other retreatment systems in the removal of root filling material. As a result of the last mentioned study [5], the null hypothesis was rejected; however, the alternative hypothesis tested was accepted. Moreover, the results of the current review study revealed that none of the examined systems were capable of the complete removal of root filling material from root canals.

In one of the six selected articles for this review study, the authors [13] concluded that the reciprocating system with adaptive motion left significantly less filling material than the other systems. This finding is consistent with those of the previous studies $[17,18]$. Another study conducted by Capar et al. [19] verified that the use of ProTaper retreatment with adaptive motion is more effective than using rotational motion. Furthermore, Bago et al. [13] reported that during the retreatment procedures, Reciproc system with M-wire alloy is more effective than Reciproc Blue with blue alloy in the removal of filling material from root canals. However, the study by Plotino et al. [20] described that the cyclic fatigue of Reciproc Blue instruments is more resistant than Reciproc instruments, which is made from M-wire.

Most systematic reviews employ Meta-analysis [21,22], which summarizes the statistics of similar data from individual studies [23]. Meta-analysis may have a more accurate overall estimate of the treatment effects; nevertheless, it cannot be used in all systematic review studies [23]. Since the studies varied in terms of retreatment and reciprocating systems, in the present review study, the authors could not use Meta-analysis. Thus, to interpret the results, descriptive evaluation was utilized.

To select the articles, following previous studies [21,22,24,25], systematic search strategy and specific inclusion and exclusion criteria were employed in the present review study. In the studies conducted by Kang et al. [22], and AlRahabi and Ghabbani [25], four electronic databases were utilized; following them, in this systematic review, four international databases were selected, which were different from those used in the above mentioned studies. The four electronic databases used in the present study were PubMed, Cochrane Library, LILACS, and SIGLE. The strength of our study in comparison to Soares et al.'s study [24] is benefiting from four databases rather than three. It is worth mentioning that in this review study, the influence of the eligibility criteria was an important factor for the selection of articles regardless of their results.

The impact metrics such as Impact Factor and CiteScore reflect the average number of citations that recently published articles in a given journal receive. The difference between Impact Factor and CiteScore is that for Impact Factor, the average number of citations is calculated over a two-year period while this period is three years for CiteScore $[26,27]$. As concluded in Cagetti et al.'s study [28], the impact metrics are recommended as quality measures for the published articles. Therefore, in the present review study the impact metrics of the journals have been taken into account. Out of the six selected articles, chosen from five journals, five were measured based on the Impact Factor of the journal in which they were published and one based on the CiteScore. It is important to note that $66.66 \%$ of the final selected journals in this review study have a JCR-Q1.

The limitation of the present review is that it did not include Endo ReStart system, since it has been manufactured only recently. So far, no studies have been conducted on this system; therefore, it could not be included in the present review study. In addition, it is suggested to conduct in vitro or vivo research studies on the efficacy of Endo ReStart system in the removal of filling material.

Finally, the results of this review study, in which six journal papers were examined, suggested that all the systems can be equally used in the removal of filling material.

\section{Conclusion}

Based on the findings of this review study on comparing the efficacy of retreatment and reciprocating files, neither reciprocating nor retreatment systems could completely remove root filling material from the root canals. Thus, it can be concluded that all the systems can be used for secondary root canal therapy. Furthermore, it is recommended that more studies be conducted on the comparison between reciprocating and retreatment systems.

\section{References}

1. Nguyen TA, Kim Y, Kim E, Shin SJ, Kim S (2019) Comparison of the Efficacy of different techniques for the removal of root canal filling material in artificial teeth: A micro-computed tomography study. J Clin Med 8: E984. [Crossref]

2. Keskin C, Sarıyılmaz E (2018) Apically extruded debris and irrigants during root cana filling material removal using Reciproc Blue, WaveOne Gold, R-Endo and ProTaper Next systems. J Dent Res Dent Clin Dent Prospects 12: 272-276. [Crossref]

3. Hulsmann M, Bluhm V (2004) Efficacy, cleaning ability and safety of different rotary NiTi instruments in root canal retreatment. Int Endod J 37: 468-476. [Crossref]

4. Tabassum S, Khan FR (2016) Failure of endodontic treatment: The usual suspects. Eur J Dent 10: 144-147. [Crossref]

5. Madarati AA, Al-Nazzawi AA, Sammani AMN, Alkayyal MA (2018) The efficacy of retreatment and new reciprocating systems in removing a gutta-percha-based filling material. J Taibah Univ Med Sci 13: 452-458. [Crossref]

6. Rodig T, Hausdorfer T, Konietschke F, Dullin C, Hahn W, et al. (2012) Efficacy of $\mathrm{D}-\mathrm{RaCe}$ and ProTaper Universal Retreatment NiTi instruments and hand files in removing gutta-percha from curved root canals - a micro-computed tomography study. Int Endod J 45: 580-589. [Crossref]

7. Fenoul G, Meless GD, Perez F (2010) The efficacy of R-Endo rotary NiTi and stainlesssteel hand instruments to remove gutta-percha and Resilon. Int Endod J 43: 135-141. [Crossref]

8. Komet Dental, Lemgo, Germany (2018) Endo ReStart, A new era in retreatments. pp 53-54.

9. de Souza PF, Goncalves LCO, Marques AAF, Junior ECS, Garcia L, et al. (2015) Root canal retreatment using reciprocating and continuous rotary nickel-titanium instruments. Eur J Dent 9: 234-239. [Crossref]

10. Rios Mde A, Villela AM, Cunha RS, Velasco RC, De Martin AS, et al. (2014) Efficacy of 2 reciprocating systems compared with a rotary retreatment system for gutta-percha removal. J Endod 40: 543-546. [Crossref]

11. Silva EJ, Orlowsky NB, Herrera DR, Machado R, Krebs RL, et al. (2015) Effectiveness of rotatory and reciprocating movements in root canal filling material removal. Braz Oral Res 29: 1-6. [Crossref]

12. Kasikci Bilgi I, Koseler I, Guneri P, Hulsmann M, Caliskan MK (2017) Efficiency and apical extrusion of debris: a comparative ex vivo study of four retreatment techniques in severely curved root canals. Int Endod J 50: 910-918. [Crossref] 
13. Bago I, Suk M, Katic M, Gabric D, Anic I (2019) Comparison of the effectiveness of various rotary and reciprocating systems with different surface treatments to remove gutta-percha and an epoxy resin-based sealer from straight root canals. Int Endod J 52: 105-113. [Crossref]

14. Delai D, Jardine AP, Mestieri LB, Boijink D, Fontanella VRC, et al. (2019) Efficacy of a thermally treated single file compared with rotary systems in endodontic retreatment of curved canals: a micro-CT study. Clin Oral Investig 23: 1837-1844. [Crossref]

15. Raj PKT, Mudrakola DP, Baby D, Govindankutty RK, Davis D, et al. (2018) Evaluation of effectiveness of two different endodontic retreatment systems in removal of Guttapercha: An in vitro study. J Contemp Dent Pract 19: 726-731. [Crossref]

16. Canakci BC, Ustun Y, Er O, Genc Sen O (2016) Evaluation of apically extruded debris from curved root canal filling removal using 5 nickel-titanium systems. $J$ Endod 42 : 1101-1104. [Crossref]

17. Silva EJNL, Belladonna FG, Carapia MF, Muniz BL, Rocha MS, et al. (2018) Microcomputed tomographic evaluation of canal retreatments performed by undergraduate students using different techniques. Restor Dent Endod 43: e5. [Crossref]

18. Kocak MM, Kocak S, Turker SA, Saglam BC (2016) Cleaning efficacy of reciproca and rotary systems in the removal of root canal filling material. $J$ Conserv Dent 19: 184-188. [Crossref]

19. Capar ID, Arslan H, Ertas H, Gok T, Saygili G (2015) Effectiveness of ProTaper Universal retreatment instruments used with rotary or reciprocating adaptive motion in the removal of root canal filling material. Int Endod J 48: 79-83. [Crossref]

20. Plotino G, Grande NM, Testarelli L, Gambarini G, Castagnola R, et al. (2018) Cyclic fatigue of reciproc and reciproc blue nickel-titanium reciprocating files at different environmental temperatures. J Endod 44: 1549-1552. [Crossref]
21. Zhang C, Liu J, Liu L (2018) The influence of ProTaper and WaveOne on apically extruded debris: A systematic review and meta-analysis. J Conserv Dent 21: 474-480. [Crossref]

22. Kang M, In Jung H, Song M, Kim SY, Kim HC, et al. (2015) Outcome of nonsurgical retreatment and endodontic microsurgery: A meta-analysis. Clin Oral Investig 19: 569582. [Crossref]

23. Siddique R, Nivedhitha MS (2019) Effectiveness of rotary and reciprocating systems on microbial reduction: A systematic review. J Conserv Dent 22: 114-122. [Crossref]

24. Soares C, Maia C, Vale F, Gade-Neto C, Carvalho L, et al. (2015) Comparison of endodontic retreatment in teeth obturated with Resilon or Gutta-Percha: A review of literature. Iran Endod J 10: 221-225. [Crossref]

25. AlRahabi MK, Ghabbani HM (2019) Influence and safety of electronic apex locators in patients with cardiovascular implantable electronic devices: a systematic review. Libyan J Med 14: 1547071. [Crossref]

26. Turner JR (2016) PubMed, PubMed central, and impact factor. Cell Mol Gastroenterol Hepatol 2: 537. [Crossref]

27. Dove C, Chan TM, Thoma B, Roland D, Bruijns SR (2019) A cross-sectional description of open access publication costs, policies and impact in emergency medicine and critical care journals. Afr J Emerg Med 9: 150-155. [Crossref]

28. Cagetti MG, Mastroberardino S, Milia E, Cocco F, Lingstrom P, et al. (2013) The use of probiotic strains in caries prevention: a systematic review. Nutrients 5: 2530-2550. [Crossref]

Copyright: (C2020 Nasiri K. This is an open-access article distributed under the terms of the Creative Commons Attribution License, which permits unrestricted use, distribution, and reproduction in any medium, provided the original author and source are credited. 